\title{
PERIFERIAS E TERRITÓRIOS SOB EFEITOS CONJUGADOS DA PRECARIZAÇÃO: algumas tendências
}

\author{
Iracema Brandão Guimarães*
}

\begin{abstract}
$\mathrm{O}$ artigo discute alguns aspectos do mundo do trabalho, considerando-o como dimensão estruturante da vida social e buscando perceber o modo como acarreta e reproduz seus efeitos de modo mais amplo. A desregulamentação do trabalho e dos direitos correspondentes, desencadeada no Brasil a partir dos anos oitenta, tornou os trabalhadores mais dependentes de políticas assistenciais e, mais especialmente, dos processos de integração primária, "proteção próxima" e vínculos, sugerindo indagar-se até que ponto esses últimos constituem ainda, prioritariamente, os elementos-chave da reprodução nos setores urbanos das periferias. Demonstra-se a existência de mudanças significativas que incidem sobre a relação família-comunidade, situada no eixo da integração primária, e discutem-se alguns dos seus efeitos e alcances efetivos com base nas teses que problematizam tais temas. O artigo prossegue com questões teóricas e metodológicas e, complementarmente, recorre a dados empíricos a fim de exemplificar alguns desses efeitos e alcances, abordando-os através da noção de territórios de precariedade situados entre a população de trabalhadores e não-trabalhadores residentes em bairros periféricos de Salvador, Bahia. PALAVRAS-CHAVE: periferia, trabalho, moradia, família, Salvador.
\end{abstract}

\section{INTRODUÇÃO}

O presente texto se reporta às transformações resultantes da desregulamentação ${ }^{1}$ e da flexibilização das relações de trabalho, convertidas em justificativas das diretrizes e políticas de redução de empregos e de tantas outras alterações hoje presentes no processo de precarização amplo e difuso que se vivencia nos últimos anos. Associadas à instabilidade da relação de trabalho (ausência

* Doutora em Sociologia pela USP. Professora Associada I do Departamento de Sociologia e da Pós-Graduação em Ciências Sociais da Universidade Federal da Bahia PPGCS/FFCH/UFBA. Pesquisadora do CNPQ e Coordenadora do Centro de Recursos Humanos CRH/FFCH/UFBA. Faculdade de Filosofia e Ciências Humanas. Estrada de São Lázaro, 197. Federação, Cep: 40.210-730. Salvador, Bahia-Brasil.iracema@ufba.br

${ }^{1}$ Para Bihr (1998, p.69-76), a crise do fordismo (compreendido como um conjunto de mecanismos de regulação), ocorrida entre o final dos anos sessenta e início dos setenta, foi marcada: pela diminuição dos ganhos de produtividade, elevação da composiçãoo orgânica do capital e saturação da norma social de consumo. Esse último aspecto é caracterizado pela inclusão de um conjunto de benefícios, tanto "em espécie" (diferentes subsídios, especialmente assistência social), como in natura (conjuntos de equipamentos e servicos coletivos à disposição dos consumidores individuais). A crise implicou a desestatização ou desmantelamento de todo um quadro institucional que havia servido de arcabouço regulador ao crescimento fordista. de contrato, de garantias, de proteção social), essas transformações se reproduzem nas outras esferas da vida social - assim como a relativa estabilidade, que caracterizava a sociedade salarial ou fordista, podia transmitir expectativas de maior garantia a essas outras esferas sociais. Isso vem suscitando uma interessante reflexão, pautada no papel do trabalho como dimensão histórica e estruturante da vida social - tal como aparece nas formulações dos clássicos a respeito do avanço da divisão do trabalho. Nesse caso, admite-se, de um modo geral, que ele é acompanhado de um deslocamento do eixo de integração social - da família-comunidade, para o mundo do trabalho e das instituições/organizações - com variadas interpretações.

Dentre elas, encontra-se uma concepção mais radical desse deslocamento nas obras de Alain Touraine (2005), e J. Habermas (1987), assim como em André Gorz (apud Abramovay, 2009, p.66), os quais supõem, como ponto em comum, a consolidação das organizações ou instituições e a sua abrangência sobre a maior parte da sociedade, colocando-lhe o desafio e o esforço de resistir a uma subordinação absoluta da vida social pelo mercado. A 
esse respeito, Oliveira (1999) argumenta que, para além do princípio do mercado, a desregulamentação e a flexibilização, com suas diferenças de intensidade e abrangência, expressam, na verdade, uma erosão da própria racionalidade burguesa.

Guardadas as diferenças que traduzem o modo como esse processo ocorreu em diferentes países, pode-se supor que, na ausência ou na presença precária (do trabalho e da proteção social) na atualidade, os trabalhadores retornam ao "mundo da integração social”, composto pelos vínculos sociais imediatos - ainda que contem, também, com as instituições assistenciais. A plausibilidade desse argumento nos coloca a questão de pensar até que ponto tais relações se constituem em elemento-chave da reprodução nos setores populares urbanos das periferias, se admitirmos que seus mecanismos não mais operem sob os mesmos referenciais da família-comunidade, pois têm passado por significativas mudanças. Isso sugere o interesse de refletir sobre o efetivo alcance e efeitos desses processos sobre as camadas populares, focalizando a sua localização no território urbano, onde a pobreza socialmente isolada se converte em exclusão social, fato tão visível atualmente nas periferias das cidades.

Discutir a visibilidade dessa questão, quanto ao alcance das redes de proteção primária na garantia da reprodução das famílias das camadas populares no contexto contemporâneo, e apreender alguns dos seus aspectos é o principal objetivo deste texto, no qual se atenta para a diversidade de relações que o problema encerra no sentido das formas de integração primária (ou instituições primordiais) que podem compensar a desestabilização no trabalho, sendo elas baseadas nas redes de "proteção próxima”, ou proteção espontânea. Entretanto, os argumentos apresentados a seguir sinalizam para rupturas e para a fragilização dessas relações, especialmente quando se referem aos determinantes em pauta: o trabalho, identificando situações que tendem a reforçar a tese do "isolamento social dos pobres" (Bauman, 2003; Katzman, 2001). Como decorrência, discute-se, também, uma sub-hipótese, qual seja: diante da ausência do trabalho regular e do capital social na sua dimensão comunitária, a vida social dos moradores das periferias urbanas se mescla com tensões e novos códigos de condutaque demarcam os territórios e suas redes de interações locais -, nos quais os agentes se defrontam com os altos índices de desemprego juvenil. ${ }^{2}$

O texto apresenta uma sistematização de alguns dos argumentos citados e se encontra organizado em três seções, que tratam, respectivamente, das seguintes dimensões: Trabalho e Moradia; Periferias Reinventadas; Território e Comunidade. Utiliza dois níveis de argumentação: primeiramente, uma reflexão teórica sobre os aspectos macroestruturais e suas implicações na dimensão da vida cotidiana; em segundo lugar, a título de exemplos, são incluídos alguns aspectos e características de um contexto empírico - os espaços residenciais de trabalhadores e não-trabalhadores precarizados, intermitentes e informais, residentes na cidade de Salvador, Bahia.

\section{TRABALHO E MORADIA: família e comunidade}

A relação entre família e comunidade tem passado por mudanças profundas, que não são diretamente causadas pelas transformações mais amplas que atingem o mundo do trabalho, mas recebe indiretamente seus impactos. No plano demográfico, a família se apresenta através de novos arranjos e relações entre as gerações, assim como das relações de gênero e poder, com importantes transformações do seu papel histórico de articulação grupal e formulação de estratégias de reprodução social e biológica. Quanto à comunidade (bairro e vizinhança), situada no plano das periferias urbanas, ela não se caracteriza apenas como o lugar por onde se passa no percurso entre casa e trabalho, tal como ocorre entre as classes médias. Ela pode ser um lugar onde se convive e se compartilham os pressupostos da sociabilida-

${ }^{2}$ Utilizamos, de início, a noção nesse sentido: os agentes demarcam os territórios e suas redes de interações locais, nos quais se defrontam com os altos índices de desemprego juvenil e de violência, uma forma de entendimento da divisão espacial da Periferia, como território "usado" (Santos, 2002). 
de, da confiança, das trocas, dos favores, ainda que também se experimente uma relativa perda do seu caráter comunitário, com várias implicações. Essa última questão tem levado Loic Wacquant (2005) a enfatizar as transformações econômicas, sociais, e políticas desencadeadas desde os anos 70 , através de impactos regressivos da decomposição salarial e das formas de socialização sobre os territórios das metrópoles, nos quais se concentram as frações vulneráveis do proletariado urbano.

A combinação (variável nos diferentes países) entre os processos de desassalariamento e de desestabilização do sistema de proteção social do trabalho traz, entre as suas consequências, uma perda do caráter comunitário existente em diferentes áreas e bairros populares das periferias de grandes metrópoles. Isso é interpretado como uma condenação da sua população à desqualificação e à segregação social, ao tempo em que a alimenta com as práticas de um capitalismo considerado predatório. ${ }^{3}$ Diante da realidade dos países que consolidaram os seus sistemas de proteção social e daqueles que o fizeram em menor grau, encontra-se a tendência à perda dos referenciais comunitários, 0 que encobre, muitas vezes, a perspectiva dos agentes. Isso não significa atribuir-se uma carga de negatividade aos agentes e a suas formas de superação, o que pode estar subentendido tanto entre aqueles que enfatizam as formas de resistência popular aos impactos do neoliberalismo, como entre os que se apoiam numa literatura cuja ênfase recai no agenciamento individual, e na busca de soluções dos problemas com base no protagonismo das famílias, das mulheres, dos jovens.

Sem negar a contribuição desse debate, o tratamento analítico da relação família-comunidade, apresentado a seguir, busca relativizar a eficácia própria das redes individuais e sociais (e suas

\footnotetext{
${ }^{3}$ Não se trata de uma categoria genérica, ou de "capitalismo selvagem", mas aqui se procura enfatizar a perda dos sistemas de proteção social especialmente no modo como isso ocorreu em alguns países europeus, o que acentua a percepção de que se entra em uma fase de grandes perdas no âmbito social, marcadas por um isolamento nos guetos, periferias, ou bairros onde habitam minorias étnicas. Utilizamos essas referências em um plano comparativo, a partir de traços gerais, para a aplicação a contextos empíricos relativamente diversos.
}

propriedades inerentes e humanitárias), sugerindo-se a necessidade de refletir até que ponto é possível à sociedade prescindir das estruturas mediadoras criadas por ela própria e expressas nas instâncias institucionais e reguladoras do Estado, das classes e das estruturas produtivas, cuja supressão, no âmbito analítico, é indicadora de um retrocesso nas conquistas dos trabalhadores. Por essa razão, as diferentes formas de precariedade, de exclusão social ou mesmo de desfiliação tornamse, mais do que antes, importantes focos de investigação para o entendimento das transformações contemporâneas. Assim, o modo como se converte a estrutura do trabalho numa instabilidade (induzida) tende a ser visto como característica dos tempos presentes, sob o foco da pós-modernidade. ${ }^{4}$ A esse respeito, Bessin (1999, apud Telles, 2006) considera que os tempos da vida e os tempos do trabalho tendem a se articular sob novas formas, não mais contidas nas relações que antes articulavam emprego e moradia, trabalho e família, trabalho e não-trabalho. A instabilidade, as jornadas irregulares de trabalho, os efeitos da flexibilização nos seus diversos aspectos se reproduzem e se difundem, mas a intermitência do trabalho (Le Marchand, 2004) não consiste somente em descontinuidade temporal: ela implica um trabalho entre zonas variadas, vários mundos de produção, dispersão espacial e outras mudanças que geram trabalhadores sazonais, tanto ligados à indústria como ao turismo, aos esportes, a várias atividades descontínuas, em função da transitoriedade entre firmas, ou entre setores. Isso caracteriza os "territórios de precariedade", e as "zonas sensíveis", sendo essas últimas os lugares de redes informais, de cooperação dos excluídos e do não-trabalho de longa duração (Le Marchand, 2004, p.53).

Dispersão espacial, atividades descontínuas,

${ }^{4}$ Tratando da sociedade pós-industrial e seus temas, discute-se a insegurança e a incerteza que a caracterizam, associando-as a um debate sobre o "mal estar da pósmodernidade". Nesse sentido, os processos da globalização e da flexibilização vêm acompanhados de sentimentos de insegurança e incertezas, frutos da mundialização econômica que transforma o mercado e, consequentemente, transforma e desestrutura o mundo do trabalho, ao tempo em que parece intensificar-se a individualização nas relações sociais. 
trabalhadores sazonais e transitoriedade, são características que estão presentes em um processo de “institucionalização da instabilidade”, cuja causa geral é a precarização do emprego e a do trabalho (Hirata; Preteceille, 2002, p.55), que produzem uma nova vulnerabilidade social de massa, e cujas raízes não se limitariam a efeitos de crises conjunturais, ou de introdução de novo modelo econômico, novas tecnologias, flexibilização do trabalho. Tanto na referência às frações vulneráveis do proletariado urbano (Wacquant, 2005) como na relativa à vulnerabilidade social de massa (Hirata; Preteceille, 2002), encontramos a conexão entre a instabilidade do mundo do trabalho e as suas repercussões sobre as outras esferas da vida social, às quais nos reportamos. Elas apontam para os sentidos do trabalho e os seus efeitos estruturantes ou desestruturantes, que constituem um importante fio condutor para a recolocação de perguntas e abordagens sobre as dimensões societárias e a ressignificação de práticas populares (Telles, 2006).

Nesses termos, um "movimento geral de precarização" se traduz nas formas de estruturação da vida social nos bairros de periferia, cada vez mais circunscritas ao improviso e à instabilidade, que parecem se tornar quase regras gerais. Isso reforça os argumentos precedentes, a exemplo do de Wacquant (2005), e também permite atribuir "um sentido teórico explícito à problemática da exclusão urbana" e abordar os "bairros em dificuldades", nos quais se acumulam processos de exclusão social e se reconhece, muitas vezes, a existência de uma estrutura social própria, através de seus modos de socialização - e também de isolamento, estigmatização, segregação (Hirata; Preteceille, 2002).

Sob esses efeitos conjugados da precarização do trabalho, e guardando uma forte dimensão cultural, não por acaso essa relação tem encontrado, no contexto latino-americano, um terreno fértil de reflexão. Kaztman (2001), num amplo esquema, analisa a inquietude e a insegurança de crescente parcela da população, através da sua ligação precária e instável com o mercado de trabalho desses países, e de seu isolamento progressivo das cor- rentes predominantes na sociedade. ${ }^{5}$ As mudanças ocorridas na estrutura social, causadoras de tal processo, para esse autor, são focalizadas através de novos mecanismos, como: (i) a redução dos âmbitos de sociabilidade informal entre as classes quanto ao uso dos mesmos serviços; (ii) a redução dos problemas de domínio comum enfrentados pelas famílias na vida cotidiana; (iii) a perda de qualidade dos próprios serviços públicos, face ao afastamento dos estratos médios do seu consumo. No plano mais específico da interação, ele destaca que o lugar do trabalho se constitui também em um meio privilegiado de construção de redes de amizades e de acesso a informações e serviços, o que caracteriza uma dimensão de capital social individualizado. ${ }^{6}$ Do mesmo modo, a participação em associações e sindicatos é representada, para ele, em duas dimensões: objetiva (direitos) e subjetiva (compartilhar problemas). E, por fim, ele chama a atenção ainda para a dimensão do capital social coletivo, que ganha expressão através das interações entre trabalhadores de distintas qualificações e categorias, na perspectiva da classe social.

Através dessas subestruturas, pode-se inferir que grandes parcelas da população não logram estabelecer vínculos estáveis e protegidos com o mercado de trabalho e desconhecem os méritos dos processos de participação e integração social, como é o caso dos jovens e também de outros grupos identificados por seus atributos. Se os efeitos

5 Sabe-se que a tese do isolamento social não é nova lembremos de Bauman (2003 p.139) que recupera a noção de comunidade, aludindo à perda de uma provável inocência, pelo progressivo isolamento social que pode acabar com os laços comunitários baseados na noção de confiança entre os atores. Isto altera o tipo de entendimento em que a comunidade se baseia, sinalizando para o fato de que as relações de comunidade, e solidariedade na modernidade seriam deslocadas pela formação das identidades de grupos que são apoiadas nos interesses comuns, sem contar com o parâmetro da localização geográfica.

Tal como é utilizado no presente trabalho, o argumento se apoia no conceito original de capital social definido por Pierre Bourdieu (1990), como segue: "A rede de ligação é o produto de estratégias de investimento social, consciente ou inconscientemente orientadas em direção à instituição ou à reprodução de relações sociais diretamente utilizaveis, em curto ou longo termo, ou seja, em direção à transformação de relações contingentes, como as relações de vizinhança, de trabalho, ou mesmo de parentesco, em relações às vezes necessárias e eletivas, implicando em obrigações duráveis (sentimentos de reconhecimento, de respeito, de amizade), ou institucionalmente garantidas (direitos)." 
estruturantes da vida social não operam, mas se deterioram e se tornam precários, suas implicações se manifestam, por exemplo, através da fragilização e da debilidade do papel do trabalho na articulação de identidades sociais, ou na exclusão de grupos de outras esferas da vida social. Concernente ao debate em questão, a maior implicação desse argumento estaria na própria concentração de famílias em condição de pobreza no espaço da moradia, tanto em decorrência de causas anteriores, como dos novos contornos adquiridos na atualidade.

A categoria dos "novos pobres" compõe, assim, as frações vulneráveis do proletariado urbano (Wacquant, 2005), assim como alimenta a vulnerabilidade social de massa (Hirata; Preteceille, 2002), direcionando o nosso olhar para um processo mais amplo que remete à própria fragmentação da classe trabalhadora (Bihr, 1998). Os critérios que permitem distingui-la, na realidade brasileira, são identificados em São Paulo por Pochman (2003):

a cidade vem sofrendo, especialmente depois de 1980, o declínio do crescimento econômico e a pressão das políticas neoliberais que estão gestando um quadro muito mais complexo de exclusão: sem que se tenha vencido a velha e tradicional exclusão, nasceu a nova.

Entre os exemplos, adianta-se que, na velha exclusão, predominava a baixa escolaridade, mas a nova exclusão independe dessa condição; na velha exclusão, predominava o determinante racial, mas, na nova exclusão, cresceu a participação da população branca, não marcadamente migrante (p.24).

Assim, os efeitos conjugados da precarização identificados a partir do impulso neoliberal das décadas anteriores remontam a um processo ainda anterior, situado por Castel (1998, p.47), ao analisar a "proteção próxima" e a sociabilidade primária (Caillé, apud Castel, 1998, p.47) como

os sistemas de regras que ligam diretamente os membros de um grupo a partir do seu pertencimento familiar, de vizinhança, do trabalho, tecendo redes de interdependência sem a mediação de instituições específicas (p.48).
Segundo ele, nas sociedades reguladas por essa interdependência, retirada de um modelo histórico, a integração primária pode ser ameaçada através dos processos de desfiliação que dissolvem os sistemas familiares e os sistemas de interdependência, fundados sobre as relações comunitárias.

Aplicando tais conceitos, Rocha (1999) aponta a existência de fatores que ameaçam os processos de integração primária, em um contexto marcado por contínuas crises econômicas e desemprego, no México. Elas provocaram uma erosão dos sistemas de apoio e proteção, conduzindo a uma busca de soluções dos problemas cotidianos através das redes sociais, da reciprocidade, da ajuda mútua, que emergiam entre trabalhadores informais como formas de amenizar a escassez do salário e os efeitos negativos das crises econômicas. Entretanto, elas nem sempre funcionam como "colchões amortecedores da pobreza", devido às mudanças na função de proteção social exercidas tradicionalmente pela família - e sua inserção na comunidade ou vizinhança -, na medida em que as redes de intercambio e reciprocidade alimentam as expectativas dos participantes de receberem bens e serviços e de retribuí-los, o que exige custos materiais, tempo, dedicação, e "disponibilidade", o que traz dificuldades de retribuição nas situações de intensa pobreza.

Esses fatores concorrem para situações de relativo isolamento social, nas quais a reciprocidade é ameaçada e se configura como um custo a mais para a pobreza (Rocha, 1999). Em tais casos, afirma a autora, os princípios de reciprocidade envolvendo solidariedade e confiança - não são vistos como naturais, espontâneos (no sentido humanitário), o que dificultaria a percepção e interpretação do quanto se encontram expostos a ameaças na contemporaneidade, configurando "rupturas do tecido social".

Stolcke (1993, p.90) analisou um contexto de migração rural-urbana e demonstrou que o parentesco e os velhos laços de amizade, que serviam como articulações (redes) no processo de migração para as cidades, persistiam por algum tem- 
po em um novo ambiente urbano. Mas as relações de vizinhança se tornavam tênues, surgindo com mais frequência o desentendimento, o conflito, a desconfiança, "um cá, outro lá”.

Na abordagem de Eguia (2004) sobre a Argentina, as redes informais de ajuda mútua são interpretadas como meios permanentes de reprodução das unidades domésticas, através da prestação de serviços gratuitos também baseados na confiança e na reciprocidade, especialmente entre pessoas unidas por relações de parentesco, vizinhança, ou amizade (p. 89). Diante da heterogeneidade da pobreza, as relações intrafamiliares com os âmbitos externos ao domicílio se apresentam como conflitivas, nas quais os membros manifestam interesses divergentes ou contraditórios e a distribuição de direitos e obrigações dependeria mais das relações de poder internas - de gênero - e menos de acordos de solidariedade, parentesco, ou vizinhança. Existe, portanto, uma probabilidade de ocorrência da mobilização de redes sociais, consideradas, nesse caso, como um atributo definidor das relações estabelecidas entre parentes, vizinhos, ou amigos (mostrando que a reciprocidade é um pressuposto, não uma regra).

$\mathrm{O}$ aumento da atividade informal e do trabalho por conta própria, nos setores de comércio, serviços e construção civil, nesse país, indica a heterogeneidade das situações e dos recursos praticados pelos grupos sociais em situações críticas de vulnerabilidade social e precarização. Eles são tratados como consumo não-mercantilizado autoabastecimento, serviços públicos gratuitos, a própria organização doméstica, compreendida como parte do processo de reprodução familiar, e a divisão sexual de trabalho - e como consumo mercantilizado - a venda da força de trabalho, própria ou familiar, vista como a mais segura maneira de maximização da renda. Quando a interação entre as unidades residenciais e de vizinhança se mantém, significa que podem continuar compartindo funções domésticas, alcançadas pela circulação e a dinâmica dos indivíduos no cotidiano dos bairros populares e espaços públicos.

Na abordagem de Pabon e Guaygua (2008) sobre a Bolívia, observa-se, também, certa multiplicidade de respostas dos trabalhadores por efeito da precarização, tanto no sentido de um aumento do trabalho no âmbito interno da família, como no sentido da maior intensidade de trabalho externo. Mas advertem para o fato de que esse aumento de esforço pode implicar a atribuição de ônus às famílias, bem como a capacidade de assumir os riscos das políticas liberais, apesar das políticas compensatórias (os programas sociais acima referidos). Como consequência, a manutenção da vida cotidiana tende a ser colocada em patamares econômicos mais baixos, exigindo das famílias uma redefinição de seus recursos e capacidades de respostas.

Sintetizando a argumentação até aqui apresentada, existiriam duas direções da relação família-comunidade em apreço. No plano interfamiliar, encontram-se as relações de confiança que são atribuídas a vizinhos e amigos, envolvendo distintos graus de reciprocidade e interação entre as unidades residenciais, nas situações em que compartilham funções domésticas. Nas unidades mais amplas, como o bairro ou a comunidade, amplia-se o foco sobre o papel-chave exercido-nesse plano da sociedade-pelas relações primárias de sociabilidade, que envolvem diferentes formas de vínculos para a obtenção de recursos não monetários - envolvendo o intercâmbio de favores e serviços os mais diversos, como o cuidado dos filhos - ou monetários, a exemplo de empréstimos financeiros (Oliveira; Sales, 1991). O acesso da população aos serviços e às políticas públicas se agrega aos recursos mobilizados pelas famílias, propiciando-lhes uma complementação da reprodução cotidiana.

No plano intrafamiliar, as normas e obrigações morais tendem a ser ressignificadas, com a individualização, a fragilização e a desestabilização das diferentes instituições sociais (inclusive o mercado de trabalho). Em muitos casos, o modelo de solidariedade e de parentesco pode continuar a apresentar sólidos laços, a exemplo da Europa do Sul, em contraste com países anglo-saxões, nos quais a família nuclear começa a tornar-se mais rara, e nos EEUU, que passou de 45 \%, em 1970, 
para cerca de $25 \%$ em princípios do século XXI (1991). Assim, na Espanha e Itália, a dinâmica familiar parece se caracterizar pela manutenção do seu papel de canalizadora e amortizadora ${ }^{7}$ das carências do Estado, mediante a contribuição das mulheres em prover cuidados não-remunerados, especialmente para crianças e idosos, o que faz recair sobre elas um protagonismo excessivo, segundo a lógica neoliberal (Vera; Diaz, 2009).

A redução de tamanho da rede de parentesco constitui um obstáculo, na medida em que afeta de maneira desigual as gerações - sendo maior para os atuais adultos e menor para as novas gerações, estreitando-se, desse modo, o âmbito de exercício da microssolidariedade (2009). Contudo, a queda da natalidade e a redução do tamanho da família não implicariam necessariamente a fragilização da solidariedade, mesmo diante da tendência à separação convivencional entre as gerações - por efeito da urbanização, da mobilidade do trabalho, e da moradia -, o que pode ser contrabalançado pelo aumento da esperança de vida, o que amplia as possibilidades de interação entre três gerações (p.126). Ainda no plano intrafamiliar, nas camadas populares, elas são consideradas mais expostas às influências externas, em função do pouco grau de autonomia do espaço privado - no sentido da privacidade -, em oposição (no plano conceitual) ao espaço público. As transformações na primeira são resultantes da interação entre as formas internas assumidas pelo seu mundo social, sendo mais marcadas por relações individuais (masculino e feminino, gênero), configuradoras da família como instituição e base da existência social. Essa argumentação avança no sentido de afirmar a importância da reflexão sobre os distintos espaços públicos como o bairro e comunidade (Cabanes, 2006).

${ }^{7}$ A questão já foi tratada em estudos anteriores: a) quanto à redução dos salários, aposentadorias e numero de pessoas cobertas por seguro social, o que também reduzia as possibilidades de a família cumprir, com a mesma eficiência da década de 70 , um papel de "amortecedora da crise" (Lautier, 1992, apud Montali, 2004 ); b) quanto às restrições encontradas pelos membros da família no mercado de trabalho, na conjuntura 1990-1994, na Região de São Paulo, Brasil, demonstrando que a capacidade de rearranjo se mantinha, embora, com menores rendimentos e maior esforço (Montali, 2004).

\section{PERIFERIAS REINVENTADAS ${ }^{8}$}

A discussão precedente consistiu em refletir sobre a ausência das estruturas do trabalho e de proteção social, ou a sua presença precária, como situações nas quais os trabalhadores passam a depender das formas de integração primária, representadas através da família e comunidade. Trabalhadores e moradores da periferia tendem a desenvolver estratégias e formas de participação que podem preencher (precariamente) a ausência daquelas estruturas institucionais, inclusive dos equipamentos urbanos, nos bairros residenciais - indicadores de sua qualidade de vida. Situando as novas realidades do trabalho e do não-trabalho, Telles (2006) observa o modo como eles "redesenham o mundo social, as relações de força e os campos de práticas que fazem a tessitura da cidade e seus espaços”, indagando até que ponto as circunstâncias do trabalho precário e intermitente alteram tempos e espaços da experiência social nos territórios da precariedade". ${ }^{9}$

Desde muito, um olhar mais atento sobre os espaços de moradia foi requisito fundamental para o seu conhecimento. A dualidade favela e cidade foi um ponto de partida de um conjunto de estudos pioneiros (referentes às décadas de quarenta e cinquenta), que adotaram um recorte racionalista, higienista ou sanitário e propunham uma visão moralista dos aglomerados populares (Valladares; Medeiros, 2003, p.10). Posteriormente, o olhar das ciências sociais se deslocou do paradigma da marginalidade social, que

${ }^{8}$ Utilizamos aqui essa referência inspirada em Valladares e Medeiros (2003, p.12). Segundo as autoras, cada novo grupo de pesquisadores "descobre" a favela segundo interesses específicos da disciplina de formação, mas deslocando-se o foco de observação do critério urbanístico para um critério social-crítico. Também, Valadares (2005) dá continuidade a essa discussão.

9 Segundo Le Marchand (2004), os "territórios de precariedade" e as "zonas sensíveis" se caracterizam como os lugares de redes informais, de cooperação dos excluídos e do não-trabalho de longa duração, abrangendo a instabilidade, as jornadas irregulares; mas a intermitência do trabalho não remete apenas à descontinuidade temporal, implicando também a existência de zonas variadas, vários mundos de produção, dispersão espacial e outras mudanças. Também Telles (2006, p.175) coloca a questão das novas realidades do trabalho (e do não-trabalho) que alteram a própria experiência urbana, seguindo os circuitos descentrados dos "territórios de precariedade" (cf. Le Marchand, 2004). 
enfatizava a integração e a organização social dos migrantes de origem rural nas grandes cidades, para a fase da "remoção das favelas", que perdurou ao longo da década de setenta, prosseguindo com os inúmeros trabalhos da década de oitenta, resultantes da ampliação dos serviços públicos. Por fim, na década de noventa, houve uma "explosão" de estudos que foi marcada tanto pela expansão do poder público como das ONGs, mas já revelando um distanciamento das práticas e posturas “anti-favela” (Burgos, 1998, apud Valladares; Medeiros, 2003, p.12).

Essa postura é identificada pela análise das causas e consequências do problema habitacional, dos déficits de moradia e das soluções espontâneas ou informais de habitação popular que caracterizam as favelas, loteamentos ou ocupações periféricas. Concentrando-se na “questão habitacional” e suas raízes no Brasil - a urbanização intensiva e o desenvolvimento industrial - esse critério aponta para as diferentes formas de produção e de apropriação do solo, resultando em configurações espaciais próprias, viabilizadas para uma grande parte da população através dos processos informais de ocupação (Souza, 2008). Já o distanciamento dessa postura se pauta pela crítica às ideias de ausência, carência e homogeneidade que tomariam como significante aquilo que a favela não é: "a favela não possui arruamento regular”; “a ocupação é ilegal”; "não há oferta formal de serviços públicos”. Assim, a noção de periferia, que foi construída a partir da experiência das favelas cariocas, é representada por um tipo de moradia considerado singular no conjunto da cidade, compondo o tecido urbano e integrado a ele (Burgos, 2008).

Observada sob um foco inovador de uma "periferia reinventada", pode-se agregar a esse foco os processos de precarização econômica e social, resgatando-se igualmente o esforço dos moradores das "comunidades" e "territórios" ao reinventarem cotidianamente a sua sobrevivência sob o olhar da positividade de suas lutas cotidianas pela sobrevivência e manutenção da dignidade de cidadãos e trabalhadores. Trata-se de um esforço a ser qualificado tanto no plano das relações comunitárias quanto no plano intrafamiliar, como indicadores de situações nas quais os interesses individuais, dispersos e sem conexão, podem de fato adquirir sentido e gerar o embrião de uma comunidade (Nunes, 2006, p.45) em contraste com o cotidiano de uma periferia dominada pelos esforços isolados de seus moradores.

O termo periferia, cujo uso é associado ao processo de urbanização dos centros brasileiros ${ }^{10}$ como sinônimo de favela, remete a essas conotações. Quando reduzido ao distante, discute-se que "a cidade contemporânea não tem mais um único centro, abrangendo lugares e sujeitos tidos como resultantes do abandono das políticas; de tal modo, que a maioria das favelas está na zona sul, na zona leste, mas também na periferia do ponto de vista econômico" (Silva, 2010). Isso mostra que o conceito é cada vez mais vinculado à ordem social e ao poder, e marcado pela questão social (2010), enquanto o critério de afastamento de um centro ou a dependência dele abarcam descritivamente uma condição social, ou um segmento da população precarizada - de baixa renda, sem rendimento fixo (2010).

\section{TERRITÓRIOS E COMUNIDADES}

A condição de trabalhador precário e de morador é, portanto, o critério que melhor qualifica a localização dos indivíduos nesses espaços sociais. Nos arredores de Brasília, observa-se que "criminaliza-se o lugar e omite-se, no mais das vezes, o fato de que as áreas com urbanização precária em nossas cidades são povoadas por famílias de trabalhadores, nas quais, muitas vezes, os cri-

${ }^{10}$ Souza (2008) destaca como a industrialização em São Paulo promoveu uma urbanização acelerada da capital, onde a crise de moradia já se manifestava, mas foi acirrada com a proliferação de diferentes tipos de cortiços e casas de cômodos, seguida de intervenções governamentais através das "vilas higiênicas", e "vilas operárias", instaladas junto às indústrias no início do século. No Rio de Janeiro, diante das más condições de vida reinantes nos cortiços e "cabeças de porco", as intervenções públicas implicaram na expulsão dos inquilinos, os quais dispunham de reduzida capacidade de renda e encontraram como alternativa habitacional a favelização dos morros no centro da cidade, processo iniciado por volta dos anos quarenta, com a sub-urbanização da população de média e baixa renda. 
minosos conseguem impor códigos de conduta”. Nesses casos, a formação de redes de solidariedade está na origem das relações de vizinhança, de aproximação, situando-se no fundo da constituição de uma comunidade (Nunes, 2006, p.46), o que encobre as imagens negativas que escondem outras, marcadas pela positividade daquela condição. Na favela RDP, no Rio de Janeiro, tais imagens reaparecem nas formas de organização local, um microsistema que articulava a vida associativa a um aparato coercitivo "e que protegia os moradores da favela da agonia da submissão ao poderio do tráfico". Isso tornou possível um regime informal de gestão do território, dando origem a uma milícia que era expressão da profunda segregação urbana a que estavam submetidas as favelas da cidade, pela impotência dos moradores diante das facções de traficantes, e entre esses últimos e os policiais - afirmados como "xerifes do território" (Burgos, 2002).

Nessas situações-limite que demarcam os embriões de comunidades e sua divisão em territórios, o primeiro conceito remonta a uma formulação complexa, presente entre autores clássicos. ${ }^{11}$ A noção de território mais recorrente compreende a forma de apropriação de um determinado espaço por um grupo social que o transforma pelo uso que lhe destina, imprimindo-lhe identidades:

... é o uso do território e, não o território em si, que faz dele objeto de análise social, o território em questão é o território usado", não apenas na dimensão do espaço físico que abriga as camadas populares, mas que engendra fatos, histórias e práticas do cotidiano das comunidades (Santos, 2002).

11 Tönnies ([1920], 1973, p.104) pensa a unidade, e a possibilidade de uma comunidade das vontades humanas, atribuídas, primeiramente, aos laços de sangue, secundariamente à aproximação espacial e, finalmente, à aproximação espiritual. Com valores analiticamente opostos ao da sociedade, na comunidade, o bem comum é um valor social, enquanto, na sociedade, predomina o individualismo. Max Weber (1994, p.247) analisa as relações de vizinhança (ou comunidade de vizinhança), afirmando que elas se referem apenas à forma "primordial" dada pela proximidade dos vizinhos, [...] "mas de modo geral, à proximidade espacial [das moradias, permanentes ou temporárias] em situação comum de interesse assim condicionada, crônica ou efêmera [...]” Ou seja, define comunidade não apenas como a proximidade espacial dos indivíduos, mas também como união de indivíduos com interesses em comum, de forma permanente ou passageira.
De modo mais específico, a noção de "territórios de precariedade” (Le Marchand, 2004) remete à intermitência do trabalho e à descontinuidade da ocupação espacial urbana, situando-a em relação à sua evolução: "a intermitência acompanha o desenvolvimento, a periurbanização", onde a diluição das cidades se efetua segundo dois tipos de movimentos: a revitalização de centros nas cidades globais grandes e pequenas, através das finanças e serviços de informação (Sassen, 1998 apud Le Marchand, 2004), e a pressão das atividades menos rentáveis em direção à periferia, em torno das quais os trabalhadores pobres oferecem seus serviços (2004, p.52). Sob esse ponto de vista, é possível observar os processos de expansão de diferentes cidades, atentando-se para bairros residenciais e periferias, cuja origem é identificada com as ocupações ou favelas, consideradas como responsáveis pelo aparecimento da maior parte das áreas urbanas ou cidades em todas as regiões do país:

... se analisarmos com os critérios do planeja-
mento urbano acadêmico formal, teremos dian-
te da vista uma experiência negativa que pode
ser relativizada sob a ótica do acesso à renda,
mostrando que as condições são diferentes, e pro-
duzem espaços também diferentes. (Nunes,
2006, p.42).

Os efeitos conjugados também estão na origem e expansão dos espaços residenciais da população de baixa renda na cidade de Salvador, atualmente a terceira maior cidade em número de habitantes do Brasil (ultrapassando os 2.631.831 habitantes). Desde os anos 1940 - período no qual se deu início à sequência das ocupações urbanas periféricas nessa cidade -, surgiram as grandes ocupações de Corta-Braço, Alagados e Gengibirra, seguindo-se um período da expansão de caráter "periférico" nos anos 50, caracterizado pelas ocupações primárias, de nível inferior, que, em grande parte, tiveram a função pioneira de conquistar novos espaços urbanos e levar à sua valorização posterior (Brandão, 1978). Com o crescimento urbano, a expansão dos meios de transportes e a abertura das primeiras grandes vias de articulação nos anos 70, desenvolveu-se uma infraestrutura 
de apoio aos polos industriais que impulsionaram a dinamização da cidade, deslocando o seu centro econômico tradicional dos Bairros do Comércio para essa nova área que ganhou, assim, uma função polarizadora, a partir da instalação do Shopping Iguatemi (em 1975), e dos novos subcentros comerciais que se seguiram.

A condição de trabalhadores e moradores está ligada à evolução do mercado de trabalho na Região Metropolitana de Salvador, que se caracterizou, posteriormente, por um aumento da precarização, ocorrido entre os anos de 1997 e 2003, e que se materializou, sobretudo, na elevação da taxa de desemprego nos anos citados, de um patamar já considerado elevado, de $21.6 \%$, em 1997, para $28 \%$ em 2003. Dentre eles, a parcela que mais cresceu foi a dos indivíduos classificados como "desempregados ocultos por trabalho precário", com um aumento absoluto de 81 mil para $127 \mathrm{mil}$ pessoas, fenômeno esse atribuído à queda dos rendimentos do trabalho (precarização) da ordem de 20 \% no período, o que levou esse amplo segmento da população baiana à busca de ocupações irregulares ou informais (Souza; Guimarães; B. Filho, 2008, p.55-57).

Na passagem dos anos 1990 para os 2000, as mudanças econômicas exerceram impactos desiguais, com uma relativa redução das assimetrias existentes por gênero, mas trazendo diferenciações de inserção entre as próprias mulheres, em decorrência dos variados níveis de pressão que elas passaram a exercer nesse mercado. Especialmente as mais jovens, na condição de filhas, foram as que mais ampliaram a participação no mercado de trabalho baiano (42,4 para 52,2 \% entre 1997 e 2003), o que sugere o desenvolvimento de estratégias de apoio às famílias, que parecem agora mais distribuídas entre os filhos de ambos os sexos (2008, p.61). Mas as oportunidades encontradas e a presença precária (do trabalho e da proteção social) sugerem, mais uma vez, um retorno ao "mundo da integração social”, composto pelos laços imediatos e vínculos, pois, mesmo contando com as instituições assistenciais, o acesso da população aos serviços e políticas públicas se agrega aos recursos mobiliza- dos pelas famílias, que lhes propiciam uma complementação da reprodução cotidiana.

A esse respeito, Ivo (2008, p.198) pontua a não-articulação desses programas com o universo do trabalho, considerando que isso "pode interferir sobre as condições de superação intergeracional da pobreza, devido à sua desconexão com a geração do emprego (especialmente frágil na região da América Latina e no Brasil)”. Desse modo, considera que, no plano da sustentabilidade e da cidadania, os beneficiados do programa Bolsa Família não têm a titularidade de um direito, como é o caso da aposentadoria, ou do Benefício de Prestação Continuada. Segundo os dados, a cobertura desse programa abrange 209.318 famílias na Região Metropolitana de Salvador, das quais 72,6 \% residem na cidade de Salvador (Ivo; Almeida, 2010).

Nessa cidade, tal como nos outros contextos observados, o aumento da atividade informal e do trabalho por conta própria se concentrou no comércio, nos serviços, e na construção civil. Esse quadro indica a heterogeneidade de situações e de recursos praticados pelos grupos sociais em situações críticas de vulnerabilidade, encontrada em diferentes bairros residenciais, classificados como as Zonas Especiais de Interesse Social - ZEIS (PDDU. Salvador, 2004), ${ }^{12}$ nos quais reside a população mais pobre da cidade e que correspondem às suas regiões periféricas, identificadas em dois planos: em um sentido restrito (Periferia tradicional), e em um sentido mais amplo (Periferia reinventada). ${ }^{13} \mathrm{O}$ primeiro coincide com o Subúr-

${ }^{12}$ Trata-se de um conjunto formado por 116 bairros identificados pelo Plano Diretor Urbano de Salvador como Zonas Especiais de Interesse Social (ZEIS), uma política pública que se baseia nos critérios da faixa de renda dos moradores e nas más condições de habitabilidade dos bairros. Isso permite operacionalizar os procedimentos para a análise de dados quantitativos e qualitativos que possam fornecer possíveis respostas à sequência das questões colocadas ao longo deste trabalho. Metodologicamente, buscamos chegar a uma seleção, com base na sua localização em três vetores de expansão urbana de Salvador: a Orla Marítima e o Centro; o Miolo Geográfico e o Subúrbio Ferroviário, localização essa que se converte em critério para estabelecer as diferenças e semelhanças quanto à origem dessas áreas residenciais como invasões, ocupações e favelas.

${ }^{13}$ Tal como já nos referimos na nota de numero 8, utilizamos aqui o termo "Periferia Reinventada" incorporando os argumentos já citados, que buscam deslocar a definição de periferia para um sentido socioeconômico, e não se referindo apenas à distância em relação a um centro. 
bio Ferroviário, onde existe maior ausência de infraestrutura e serviços básicos, abrigando atualmente cerca de 620 mil moradores no seu conjunto.

Desde a criação da Região Metropolitana de Salvador, em 1972, o Subúrbio Ferroviário é definido como periferia. Se é verdade que não está desarticulada do restante e se afirma não pela exclusão, mas pelo papel que exerce em um contexto mais amplo da cidade, a antiga e tradicional periferia se caracteriza pelos circuitos sociais que articulam os seus moradores e trabalhadores ao restante da cidade. Nos bairros de Alagados, S. João do Cabrito, Plataforma, Rio Sena, Periperi, Fazenda Coutos, Nova Constituinte, Coutos, Paripe e Lobato, abriga-se uma população majoritariamente sem vínculo empregatício (precarização por trabalho irregular e ausência de proteção). Neles, verifica-se a ampla presença de mulheres responsáveis por domicílios, que exercem atividades na prestação de serviços domésticos e outros serviços pessoais, e que se encontram em proporção significativa na linha de pobreza (18\% tem rendimento entre 0, 5 e 1 salário mínimo) (Guimarães, 2005). No plano intrafamilar, existe uma média alta de moradores por domicílio e elevada carga de dependência, com filhos pequenos e outros parentes.

No plano interfamiliar, a residência no bairro há cerca de dez anos, em média, leva as moradoras ao afastamento das famílias de origem (residentes em áreas rurais ou bairros distantes), e à convivência com situações de fragilização da rede familiar como âmbito de exercício da solidariedade. Na vida cotidiana, elas afirmam, em relação à rede de apoio: "Os parentes estão longe"; "A família mesmo é mais difícil, torna-se mais fácil contar com um estranho"; "Ter um bom amigo vale mais do que parente"; "Não recorro à família, apesar de me relacionar bem com irmãos" (Guimarães, 2002). Assim, se a vizinhança é uma vivência comum em relação ao espaço público (a rua), as famílias das camadas populares são mais expostas às influências externas e apresentam pouco grau de autonomia do espaço privado em relação ao seu mundo social e a espaços públicos - bairro, comunidade (Cabanes, 2006).
As relações de vizinhança, à primeira vista, são apresentadas sob a forma da cordialidade: "Todo mundo se dá, me relaciono com todos"; "Aqui não tenho o que dizer dos meus vizinhos”. Mas, indo além da aparência, o distanciamento se faz presente e sinaliza para as rupturas e perdas do caráter comunitário, que são exemplares nas situações comuns a dois bairros: "Todo mundo se dá, mas não conto muito com vizinhos, não costumo conversar sobre problemas pessoais." (Bairro de Coutos, Subúrbio Ferroviário). "Não gosto muito de envolvimento com vizinhos, é bom a gente cá e ele lá, aprendi com minha avó."; "Eu aqui não vou à casa de ninguém, agora, se precisar de ajuda, eu dou, aí é diferente."; "Gosto dos vizinhos, mas eles lá e eu cá."; "Porque eu só vivo dentro de casa, não tenho aproximação com ninguém assim $d a$ rua, tem gente aí que eu nem conheço." (Bairro do Uruguai, Subúrbio Ferroviário).

A sociabilidade primária (familiares, amigos ou vizinhos) também parece relativamente ameaçada em diferentes bairros da cidade, contribuindo para um relativo isolamento social e uma fragilização das relações de interdependência que fundam as relações comunitárias e que podem ser mobilizadas em ocasiões especificas, diante de situações de maior gravidade, quando envolvem problemas de saúde e acidentes (Guimarães, 2002). No âmbito da "Periferia Reinventada", situam-se alguns dos bairros mais populosos de Salvador, a exemplo de Liberdade e São Caetano, esse último com uma população de 49.459 habitantes, em sua maioria de renda baixa, com predominância da atividade comercial, seja no comércio estabelecido (lojas de calçados, vestuário, móveis, mercados e supermercado), seja na informalidade, que se localiza em quase a totalidade da via principal do bairro, com ocupação das calçadas por camelôs e similares, que passam a constituir a paisagem local. Trata-se de um comércio de gêneros alimentícios e também de vestuários, artigos eletrônicos de baixa tecnologia e mesmo mercadorias ilegais, além da prestação de serviços em geral, como reparações realizadas no próprio local. As mercadorias e os serviços oferecidos atendem à demanda de con- 
sumo dos habitantes do bairro e dos próximos (como Capelinha e Boa Vista de São Caetano), caracterizados por um baixo poder aquisitivo (Souza, 2010).

Os bairros de São Marcos e Pau da Lima formam um complexo que se expandiu nas terras que pertenciam ao Mosteiro de São Bento até 1917, quando o município de Salvador adquiriu parte do território e procedeu a aforamentos que deflagraram a ocupação popular durante a expansão de caráter "periférico", datada dos anos 50 (Brandão, 1978). As baixadas, ou fundos de vales, foram destinadas para a população mais pobre, entre elas as áreas de Baixa Fria e Baixa de Santa Rita, que abrigam cerca de 734 famílias, entre as quais predominam os trabalhadores autônomos, biscateiros, pedreiros, ou subempregados. A partir da consolidação da região do Miolo Geográfico, atualmente esses bairros, no seu conjunto, são integrados por uma população estimada em 120 mil habitantes.

Localizado entre as encostas da Orla Marítima da cidade, o Nordeste de Amaralina agrega os bairros da Santa Cruz, Vale das Pedrinhas e Chapada do Rio Vermelho, abrigando uma população de mais de 83 mil habitantes (IBGE, 2000). Nele, $88 \%$ dos moradores são identificados como de cor parda ou negra; 49 \% têm menos de 25 anos de idade e apenas $9 \%$ têm mais de 55 anos. Na condição de trabalhadores e moradores do bairro, apenas $49 \%$ fazem parte da população economicamente ativa com uma atividade remunerada, indicando um contexto de precarização que tem sido marcado por um intenso aumento da violência, identificada por pesquisa realizada pelo Fórum Comunitário de Combate à Violência. Em razão disso, existem tentativas de reconstituição da vida comunitária, lideradas por organizações comunitárias e ações culturais presentes no bairro (Souza, 2007). Em um cenário semelhante ao dos demais bairros citados, à primeira vista, as relações de vizinhança também são mais marcadas pela cordialidade, a exemplo de uma moradora que considerou a convivência boa no bairro. Porém, indo além da aparência, o distanciamento e a individualização tam- bém se fazem presentes em um segundo momento, e uma moradora afirma que a única situação na qual se precisou dos vizinhos teria sido para ir ao médico: para D. Marlene é "cada um na sua". ${ }^{14}$

Os bairros do Alto do Cabrito e Marechal Rondon foram ocupados desde o século XIX, tendo o seu povoamento modificado durante a expansão de caráter "periférico", datada dos anos 50 (Brandão, 1978), em virtude da instalação de uma fábrica, e, nos anos 70, com a chegada de grande numero de famílias desabrigadas. Abrangendo dois bairros, Marechal Rondon e Campinas do Pirajá, essa área conta com uma população aproximada de 25 mil habitantes (IBGE, 2000), dos quais 95,7\% não nasceram no município de Salvador e 83,5\% são pardos e pretos A presença de certo numero de moradores vinculados por grau de parentesco contribuiu para a construção de laços comunitários mais sólidos, atribuídos, principalmente, à presença de três associações comunitárias e de instituições religiosas, as quais influenciaram a organização dos moradores em anos anteriores, permitindo-lhes uma atuação organizada diante do poder público municipal e dos órgãos responsáveis por uma intervenção que implicava a remoção de cerca de 400 famílias residentes. Tratando-se da implantação de um amplo projeto de urbanização, isso originou um processo de resistência local, desencadeado em torno do objetivo de garantia do lugar de moradia (Santos, 2006). Nesse caso confirma-se o argumento de Nunes (2006, p.45) de que os interesses individuais, dispersos e sem conexão podem, de fato adquirir sentido e gerar o embrião de uma comunidade, em contraste com o cotidiano de uma periferia dominada pelos esforços isolados de moradores em sua luta pela sobrevivência.

\section{CONCLUSÕES}

Oenfoque empírico apresentado é ilustrativo dos "Territórios de Precariedade" no sentido am-

\footnotetext{
Guimarães, Iracema, "Trabalho, Família e Gênero em áreas urbanas de pobreza“, Projeto CNPQ, 2008-2011. Entrevistas e etnografia do bairro realizadas por Amanda Souza e Isa Farias dos Santos, Pibic, maio-agosto, 2010
} 
plo que buscamos discutir, nos quais predominam os esforços isolados de seus moradores em luta pela sobrevivência. A apropriação do território por atividades que agreguem os moradores, centradas na relação entre família e comunidade, apresenta uma tendência a uma mudança que segue na direção da fragilização dos laços comunitários, embora as situações que favorecem a agregação façam a diferença. No mais das vezes, os bairros são percorridos pelos novos processos em discussãotrabalho precário e desemprego, fragilização dos apoios nas relações de confiança e reciprocidade-, as quais alteram o próprio uso do espaço público (a rua, a vizinhança). No contexto empírico observado na cidade de Salvador, eles afetam sobremodo as relações em apreço, e o aumento da violência constitui um capítulo à parte, constatando-se, segundo a imprensa local, que o Subúrbio Ferroviário é hoje a maior circunscrição policial da cidade, onde foram registradas 105 ocorrências de homicídios entre fevereiro e junho de $2010 .{ }^{15}$

Trata-se, portanto, de um cenário no qual incidem os fatores de instabilidade, insegurança e incertezas que atravessam as diferentes dimensões da vida cotidiana, restringindo as perspectivas e distanciando os moradores. Em algumas situações observadas, a relação entre família e comunidade tende a ser submetida ao controle de outros grupos (Burgos, 2002), em uma realidade que confirma a probabilidade de ocorrência da mobilização de redes sociais, consideradas, nesses casos, como atributos definidores das relações estabelecidas entre parentes, vizinhos, ou amigos (Eguia, 2004). Tais redes fundamentam uma sociabilidade primária submetida a ameaças que afetam, de modo relativo, o seu papel de complementação da reprodução da força de trabalho (Rocha, 1999).

Existem argumentos favoráveis que buscam apreender o funcionamento das redes informais

${ }^{15}$ Em reportagem do jornal A Tarde, datada de 18/07/10, apresentou-se um ranking dos lugares mais violentos da cidade de Salvador, partindo do dado de que 736 assassinatos foram registrados em toda a cidade, entre fevereiro e junho de 2010. Em números absolutos, o maior número de mortes ocorreu em: Periperi, Nova Constituinte e Vista Alegre (35 casos), bairros situados no Subúrbio, ou na Periferia Tradicional, seguindo-se, São Caetano (30) Sussuarana (22) e Lobato (22). de ajuda mútua de modo mais autônomo. Desde que se esclareça e identifique "onde" e "quando" elas tendem a ocorrer, podem ser interpretadas como meios permanentes de reprodução das unidades domésticas, através da prestação de serviços gratuitos baseados na confiança e na reciprocidade. Mas é necessário indagar até que ponto a noção de comunidade, aplicada às relações de vizinhança, revela o seu efetivo papel nas trocas de serviços e na solidariedade que podem amenizar a experiência da pobreza, discutindo-se as formas de participação, a busca de diferentes soluções, informações, e mesmo o acesso às diferentes instituições e políticas públicas.

Nesse sentido, um interesse renovado encontra-se nas metodologias de pesquisa que introduzem novos parâmetros sobre a questão. Marques e Bichir et al. (2010) consideram que as redes sociais são centrais na sociabilidade dos indivíduos e no seu acesso aos mais diferenciados elementos materiais e imateriais. Nos debates sobre a pobreza, as redes são citadas como fatores-chave na obtenção de empregos, na organização comunitária e política, no comportamento religioso e na sociabilidade em geral. Segundo os autores, através de pesquisas, o conhecimento das formas de estruturação das redes de indivíduos pobres permite o entendimento de suas trajetórias, de seu cotidiano e de suas estratégias de sobrevivência. Isso também aponta para processos sociais que contribuem para a reprodução da pobreza em um sentido mais amplo. Na variada literatura tratada, a diferenciação das redes a partir de padrões que constituem um dos principais traços diferenciadores da sociabilidade moderna, baseia-se em uma grande quantidade de vínculos secundários, bastante heterogêneos em conteúdo, fracos em intensidade, e não necessariamente organizados territorialmente, ao contrário dos padrões característicos do mundo rural e das cidades pequenas.

Assim, a vida nas grandes cidades, apoiada nas novas técnicas de comunicação e transporte, ajuda a superar as barreiras físicas da vizinhança e da comunidade. Segundo Ferrand (apud Marques; Bichir et al, 2010), os estudos sobre a pobreza ur- 
bana apresentam o fator espacial-geográficoterritorial, que constitui um elemento-chave da sociabilidade, indicando que, entre as populações pobres, as interações sociais ainda se constituem "porta a porta" (vizinhança), conduzindo ao estudo da composição típica das microestruturas no interior de comunidades ou bairros. Esse argumento representa, portanto, um forte apelo para a continuidade de pesquisas baseadas nas novas concepções de redes pessoais e sociais que possam acrescentar e lançar novas luzes ao conjunto dos argumentos apresentados.

Prevalece a tese do "isolamento social dos pobres", a segregação na vida urbana, na qual o mundo da integração social composto por laços imediatos de vínculos aponta para o seu funcionamento para dentro, no interior dos bairros, territórios e comunidades que representam os seus próprios limites, porque não abrem a possibilidade de mobilidade entre as classes sociais. Um argumento favorável pode ser encontrado em Nunes (2006), ao procurar mostrar em que situação pode ressurgir um "embrião" de comunidade, pela união ou integração de interesses que geralmente se encontram dispersos, situação comparável à que aconteceu no exemplo citado do bairro de Marcehal Rondon, em Salvador, através da organização popular e da resistência à intervenção do poder público.

Por fim, considerados à luz da categoria da subalternidade, uma parte desses argumentos remonta às relações de favor e amizade focalizadas no plano das relações entre as classes e da sua conotação de relações pessoais que se dão em detrimento da lei e dos direitos, distinguindo-se a pessoa do indivíduo, como forma de indicar a predominância das relações pessoais, do favor e da amizade, mas em um contexto de cultura subalterna e autoritária (Da Matta, 1991). Dentro de um marco teórico específico, diferentes autores discutiram a existência de uma pesada herança de clientelismo, do favor e da ajuda (relações pessoais) que apontava para uma antimodernidade, na qual a "malha protetora" dos trabalhadores brasileiros incluiria as redes de mobilização comunitárias e familiares (nosso argumento). Tais redes são consideradas como parte de uma cultura política que redefiniu padrões de paternalismo, principalmente diante do fato de que o Brasil não alcançou a institucionalidade europeia (Yazbek, 2010).

(Recebido para publicação em 14 de fevereiro de 2011) (Aceito em 09 de maio de 2011)

\section{REFERÊNCIAS}

ABRAMOVAY, Ricardo. Anticapitalismo e inserção social dos mercados. Tempo Social, São Paulo, v. 21, n. 1, p.6587, jun., 2009.

BAUMAN, Zygmunt. Comunidade: a busca por segurança no mundo atual. Rio de Janeiro: Zahar Ed;,2003.

BHIR, Alain. Da grande noite à alternativa: o movimento operário europeu em crise. São Paulo: Boitempo Editorial, 1998.

BOURDIEU, Pierre. Le capital social, notes provisoires. Actes de la Recherche, Paris, n.31, 1990.

O capital social - notas provisórias. In: NOGUEIRA, M. A.; CATANI, A. (Org.) Pierre Bourdieu: escritos de educação. Petrópolis: Vozes, 1998.

BURGOS, Marcelo. Favela e luta pela cidade: esboço de um argumento. In: SILVA, Jailson de Souza e. O que é favela, afinal? Rio de Janeiro: Observatório de Favelas, 2009. (Coletânea de textos) Disponível em: www.comunidadesegura.org. Acesso em: 20 set 2010

Utopia da comunidade: Rio das Pedras, uma favela carioca. Rio de Janeiro: Editora Puc-Rio/Loyola, 2002 .

BRANDÃO, Maria de Azevedo. Origens da expansão periférica de Salvador. Revista Planejamento, Salvador, Seplantec/ CPE, v.6, n.2, 1978.

CABANES, Robert. Espaco privado e espaço público: o jogo de suas relações. In: TELLES, Vera da S.; CABANES, Robert. (Org.) Nas tramas da cidade: trajetórias urbanas e seus territórios. São Paulo: Associação Editorial Humanitas, 2006.

CASTEL, Robert. A proteção próxima. In: . As metamorfoses da questão social: uma crônica do salário. Petrópolis: Ed. Vozes, 1998. (Serie zero à esquerda).

DA MATTA, Roberto. A casa \& a rua: espaço, cidadania, mulher e morte no Brasil. Rio de Janeiro: Guanabara Koogan, 1991.

EGUIA, Amália. Pobreza y reproduccíon familiar: propuesta de um enfoque para su estúdio. Caderno CRH: Centro de Recursos Humanos da UFBA, Salvador, v.17, n.40, p.7992, jan./abr. 2004.

GUIMARÃES, Iracema Brandão. Moradia, família e trabalho: demandas urgentes na experiência popular. In: LIMA P. Costa, (Org.) Quem faz Salvador? UFBA/Prefeitura Municipal de Salvador, 2002.

Diferenciação dos arranjos domiciliares e espaCo social Urbano. Caderno CRH: Centro de Recursos Humanos da UFBA, Salvador, n.43, p.57-70, 2005.

Trabalho, família e gênero em áreas urbanas de pobreza. Projeto CNPQ, 2008-2011. 
HIRATA, Helena; PRETECEILLE, Edmond. Trabalho, exclusão e precarização socioeconômica, o debate das ciências sociais na França. Caderno CRH: Centro de Recursos Humanos da UFBA, Salvador, n.37, 2002.

IBGE. Atlas do Desenvolvimento Humano da Região Metropolitana de Salvador, 2000.

IVO, Anete B. L. Viver por um fio: pobreza e política social. São Paulo: AnnaBlume Ed., 2008. (Coleção trabalho e contemporaneidade)

; ALMEIDA, Patrique. Vulnerabilidade, pobreza e assistência: a segmentação da assistência pública. Projeto do PIBIC/CNPq/UFBA 2009-2010. Salvador: UFBA, 2010.

KAZTMAN, Ruben. Seducidos y abandonados: el aislamiento social de los pobres urbanos, Revista de la CEPAL, Santiago de Chile, n.70, 2001.

LE MARCHAND, Arnaud. Travail intermittent et production de la ville post-fordiste. Multitudes, Paris, n.17, été, 2004.

MARQUES, Eduardo; BICHIR, Renata et al. Redes pessoais e pobreza em São Paulo. Disponível em: www.win3pdf.com. Acesso em: 12 abr. 2010

MONTALI, Lilia. Família e trabalho na reestruturação produtiva: ausência de políticas de emprego e deterioração das condições de vida. Revista Brasileira de Ciências Sociais, São Paulo, v.15, n.42, p.55-71, fev.2004.

NUNES, Brasilmar Ferreira. O sentido urbano de ocupacões espontâneas do território: uma periferia de Brasília. In: NUNES, B. F. (Org.) Sociologia das capitais brasileiras: participação e planejamento urbano. Brasília, DF: Líber Livro Ed., 2006.

OLIVEIRA, Francisco. Para além do princípio do mercado. Revista Latinoamericana de Estudos del Trabajo, Mendoza,Ar, v. 5, n.9, 1999.

OLIVEIRA, Orlandina de; SALLES, Vânia. Reprodução social e reprodução da força de trabalho, Caderno $C R H$ : Centro de Recursos Humanos da UFBA, Salvador, n.14, p.22-32, 1991

PDDU. Plano Diretor de Desenvolvimento Urbano. Retirado do glossário do PDDU- Salvador. Disponível em: www.seplam.pms.ba.gov.br/pddua/anexos/anexo90.htm. Acesso em: 10 set. 2008 .

PABÓN, Silvia Escóbar; GUAYGUA, Germán. Estratégias familiares de trabajo y reduccion de la pobreza en Bolívia. Buenos Aires: Clacso, 2008.

POCHMANN, M; GUERRA, A. Trabalhadores urbanos, ocupação e queda de renda. São Paulo: Cortez, 2007.

ROCHA, Mercedes Gonzáles de la. La Reciprocidad amenazada: un costo a mas de la pobreza urbana. Revista Latinoamericana de Estudos del Trabajo, Mendonza,Ar, v.5, n.9, 1999.

SANTOS, Milton. O retorno do território. In:

SOUZA, Maria Adélia de; et al. Território, globalização e fragmentação. São Paulo: ANPUR, 2002.

SANTOS, Ademir Souza. Modernização da capital baiana pós 1990 e o movimento de luta pela moradia: o caso do Dique do Cabrito. 2006. Dissertação (Mestrado) - Universidade Federal da Bahia. Salvador, 2006.

SILVA, Jailson de Souza. ONG observatório de favelas do Rio de Janeiro. Disponível em: www.favelaeissoai.com.br/ noticias.php. Acesso em: 10 nov. 2010

SOUZA, Ângela Gordilho. Limites do habitar: segregação e exclusão na configuração urbana contemporânea de Salvador. Salvador: Edufba, 2008.

SOUZA, Laumar Neves; GUIMARÃES, Iracema Brandão; B. FILHO, Leormínio M. (Des)igualdades nas estratégias de inserção feminina durante a exacerbação da crise do mercado de trabalho na Região Metroplitana de Salvador. Revista da ABET: Associação Brasileira de Estudos do Trabalho, São Paulo, v.7, n.2, p.50-75 jul./dez., 2008.

SOUZA, Flávia. Economia (da periferia) urbana: a informalidade no bairro de São Caetano, Subúrbio Ferroviário de Salvador. In: Seminário de Políticas Sociais e Cidadania,3, 2010. Anais.... Salvador: UCSAL, 2010.

SOUZA, Tatiane dos Santos. Novo olhar sobre a região Nordeste de Amaralina: o impacto das acões culturais do Programa Viva Nordeste, $3^{\circ}$ Enecult. Salvador: UFBA, 2007.

STOLCKE, Verena. A família que não é sagrada.In:

Colcha de retalhos: estudos sobre família no Brasil. São Paulo: Editora Unicamp, 1993.

TELLES, Vera da Silva. Nas franjas da cidade global: tudo certo, tudo em ordem? In: ; CABANES, Robert, (Org.) Nas tramas da cidade: trajetórias urbanas e seus territórios. São Paulo: Ass. Editorial Humanitas, 2005.

Mutações do trabalho e experiência urbana. Tempo Social: revista de Sociologia da USP, v.18, n.1, p.173195, 2006.

TONNIES, Ferdinand. Comunidade e sociedade como entidades típico ideal. In: FERNANDES, Florestan (Org.). Comunidade e sociedade: leituras sobre problemas conceituais, metodológicos e de aplicação: São Paulo: EDUSP Nacional, 1973.

VALADARES, Lícia do Prado; MEDEIROS, Lidia. Pensando as favelas do Rio de Janeiro 1906-2000. Rio de Janeiro: Faperj/ Relume-Dumará, 2003.

A invenção da favela: do mito de origem a favela.com. Rio de Janeiro: FVG, 204 p.2005 .

VERA, Pedro Sánchez; DIAZ, Marcos Bote. Familismo y cambio social. El caso de España. Sociologias: revista semestral do Programa de Pós-Graduação em Sociologia da UFRGS, Porto Alegre, v.11, n.21, p.121-149, 2009.

YAZBEK, Maria Carmelita. Classes subalternas e assistência social. São Paulo: Cortez, 2007.

WACQUANT, Löic. Os condenados da cidade, estudos sobre marginalidade avançada. Rio de Janeiro: Ed. Revan, 2005 


\section{PERIPHERIES AND TERRITORIES UNDER THE COMBINED EFFECTS OF PRECARIZATION: some tendencies}

\author{
Iracema Brandão Guimarães
}

This paper discusses some aspects of the world of labor, considering it as a structuring dimension of social life and seeking to realize how it brings and reproduces its effects more broadly. The deregulation of labor and its corresponding rights, triggered in Brazil since the eighties, made workers become more dependent on welfare policies and, more specifically, on the primary processes of integration, "close protection", and bonds, suggesting the question "to what extent do these bonds still constitute, prioritarily, the key elements of reproduction in urban areas on the periphery. It is shown that there are significant changes, focusing on the relation family-community, located on the axis of the primary integration, and one discusses some of their effective scope and effects based on the actual thesis analyzing such issues. This paper goes on to theoretical and methodological issues and, in addition, uses empirical data to illustrate some of these scope and effects, addressing them through the notion of territory of precariousness located among the population of workers and nonworking people living in peripheric neighborhoods in Salvador, Bahia.

KEYwORDS: periphery, work, housing, family, Salvador

\section{PÉRIPHÉRIES ET TERRITOIRES SOUS L'EFFET CONJUGUÉ DE LA PRÉCARISATION: quelques tendances}

\author{
Iracema Brandão Guimarães
}

L'article traite de certains aspects du monde du travail, considéré comme dimension structurante de la vie sociale, et essaie de percevoir la manière de produire et de reproduire plus largement ses effets. La déréglementation du travail et de ses droits y relatifs, qui s'est déclenchée au Brésil dans les années quatrevingts, a rendu les travailleurs plus dépendants de politiques d'assistance et tout spécialement de processus d'intégration primaire, de "protection proche" et de liens, ce qui incite à savoir jusqu'à quel point ces derniers ne constitueraient pas, encore et de manière prioritaire, les éléments clés de la reproduction dans les zones urbaines de la périphérie. Il est démontré que des changements importants ont lieu, qu'ils ont une influence sur la relation famille-communauté qui se trouve dans l'axe de l'intégration primaire et certains de leurs effets et répercussions effectives sont discutés sur la base des thèses qui soutiennent ces thèmes. Larticle traite ensuite des questions théoriques et méthodologiques et utilise de manière complémentaire des données empiriques afin de montrer des exemples de ces effets et de leur portée qui sont traités par le biais de la notion de territoires de précarité situés entre la population des travailleurs et des non-travailleurs habitants dans les quartiers de la périphérie de Salvador, Bahia.

MoTS-CLÉs: périphérie, travail, habitation, famille, Salvador. 